\title{
Evaluation and management of Cushing syndrome in cases of negative sellar magnetic resonance imaging
}

\author{
Jay Jagannathan, M.D., Jason P. Sheehan, M.D., Ph.D., and John A. Jane JR., M.D. \\ Department of Neurosurgery, University of Virginia Health Sciences Center, University of Virginia, \\ Charlottesville, Virginia
}

\begin{abstract}
$\checkmark$ The treatment of patients with Cushing disease and without magnetic resonance (MR) imaging evidence of Cushing disease (that is, negative MR imaging) is discussed in this paper. Magnetic resonance imaging is the diagnostic modality of choice in Cushing disease, but in up to $40 \%$ of these patients negative imaging can be caused by tumor-related factors and limitations in imaging techniques. In cases in which the MR imaging is negative, it is critical to make sure that the diagnosis of Cushing disease is correct. This can be accomplished by performing a complete laboratory and imaging workup, including dexamethasone suppression tests, imaging of the adrenal glands, and inferior petrosal sinus sampling when appropriate. If these evaluations suggest a pituitary source of the hypercortisolemia, then transsphenoidal surgery remains the treatment of choice. The authors favor the endoscopic approach because it gives a wider and more magnified view of the sella and allows inspection of the medial cavernous sinus walls. Radiosurgery is an effective treatment option in patients with persistent Cushing disease. When a target cannot be found on MR imaging, one can target the entire sellar region with radiosurgery. (DOI: 10.3171/FOC-07/09/E3)
\end{abstract}

\author{
KeY WORDS • Cushing disease • Gamma Knife • magnetic resonance imaging • \\ outcome $\bullet$ pituitary $\bullet$ pseudocapsule $\bullet$ radiosurgery $\bullet$ surgery
}

$\mathrm{C}$ USHING disease is a neuroendocrine disorder associated with multiple potentially devastating side effects related to cortisol hypersecretion. ${ }^{7,22,47}$ Magnetic resonance imaging is the imaging modality of choice in patients with suspected Cushing disease. Accurate preoperative imaging localization of ACTH-secreting microadenomas is important, as it seems to be correlated with a significantly better surgical outcome. ${ }^{3,5}$ However, conventional MR imaging can be negative in up to $40 \%$ of cases, complicating surgical treatment. ${ }^{39}$ In this paper we review the management strategies of Cushing disease in patients with negative MR imaging.

\section{Evaluation and Management of Cushing Syndrome \\ Establishing the Diagnosis}

Special care must be taken to establish that the pituitary is the source of excess ACTH secretion in patients with negative MR imaging. The differential diagnosis of Cush-

\footnotetext{
Abbreviations used in this paper: $\mathrm{ACTH}=$ adrenocorticotropic hormone; $\mathrm{CRH}=$ corticotrophin-releasing hormone; $\mathrm{CSF}=$ cerebrospinal fluid; LINAC = linear accelerator; MR = magnetic resonance; SPGR = spoiled gradient recalled acquisition in the steadystate; UFC = urinary free cortisol.
}

ing syndrome is broad and includes adrenal tumors, ectopic ACTH production (rare in the pediatric population), and ectopic CRH-producing tumors. ${ }^{13}$ In a child or adolescent with suspected Cushing syndrome, the diagnosis may be problematic not only because these tumors are often not evident on MR imaging, but because pseudo-Cushing's states can be difficult to distinguish definitively from true Cushing disease..$^{15}$ Pseudo-Cushing syndrome results in a hypercortisolemic state and may also be associated with physical features indistinguishable from those of Cushing disease. It results from an underlying disease process, such as depression or obesity, although the precise mechanism remains unclear. Unlike Cushing disease, however, pseudoCushing states almost always resolve with treatment of the underlying disease. Hence, the initial examination of a patient suspected of having Cushing disease should screen for disorders that result in pseudo-Cushing syndrome. ${ }^{1}$

Screening for hypercortisolemia involves a 24-hour urinary free cortisol or low-dose dexamethasone suppression test. Urinary free cortisol values greater than 220 to 330 nmol/24 hours (range 80-120 ng/24 hours) are sensitive, but relatively nonspecific, for a diagnosis of Cushing syndrome. ${ }^{28}$ Failure to suppress morning ( 8 a.m.) serum cortisol levels to 100 to $200 \mathrm{nmol} / \mathrm{L}$ (range $3.6-7.2 \mathrm{ng} / \mathrm{dl}$ ) the morning following a midnight dose of 0.5 to $2.0 \mathrm{mg}$ of dexamethasone also indicates Cushing syndrome. ${ }^{28}$ Sup- 
pression to less than $50 \mathrm{nmol} / \mathrm{L}$ or $1.8 \mathrm{ng} / \mathrm{dl}$ is highly specific for the exclusion of Cushing syndrome. When doubt remains as to the possibility of pseudo-Cushing syndrome, a combined CRH-low-dose dexamethasone suppression test may be used. As described, patients receive $0.5 \mathrm{mg}$ of dexamethasone every 6 hours for 24 hours followed by a 1 $\mathrm{ng} / \mathrm{kg}$ intravenous dose of CRH. ${ }^{25,27,28}$ In patients with Cushing syndrome, $\mathrm{CRH}$ should overcome the suppressive effects of dexamethasone, and the serum cortisol level at 15 minutes should be greater than $1.4 \mathrm{ng} / \mathrm{dl}$. A single midnight serum cortisol reading reportedly has an excellent sensitivity for diagnosing Cushing syndrome, but its specificity remains uncertain due to the lack of adequate control groups. ${ }^{34,35}$ The measurement of cortisol levels in the saliva has been reported in the diagnosis of Cushing syndrome and has several advantages over serum cortisol levels: it is a noninvasive measurement, is useful when blood sampling is difficult, and eliminates the confounding effects of cortisol elevation from venipuncture. In addition, it is an accurate index of free, biologically active serum cortisol, ${ }^{6}$ unaffected by the estrogen milieu, which is known to increase corticosteroid-binding globulin levels. Salivary cortisol measurements are an alternative to UFC in patients who fail to properly collect urine over 24 hours. ${ }^{36}$

Once the presence of Cushing syndrome has been established, the source of cortisol excess must be determined. Although low ACTH levels $(<5 \mathrm{pg} / \mathrm{ml})$ exclude Cushing disease, higher levels require further testing to distinguish a pituitary from an ectopic source of ACTH secretion. No single test provides an absolute distinction, but the combined results of several tests generally provide a preponderance of evidence. These tests include the high-dose dexamethasone suppression test, dynamic testing with metyrapone (750 mg every 4 hours for six doses) or CRH (1 $\mathrm{ng} / \mathrm{kg}$ intravenously), and inferior petrosal sinus sampling. ${ }^{29}$ The high-dose dexamethasone suppression test is used to compare steroid levels (either serum cortisol, 24hour urinary 17-hydroxycorticosteriods, or 24-hour UFC) prior to and the morning after either a 2-mg dose of dexamethasone every 6 hours for 48 hours or after a single 8$\mathrm{mg}$ dose of dexamethasone administered in the evening (11 p.m.). Patients with pituitary-dependent ACTH secretion should suppress serum cortisol more than $50 \%$, UFC more than $90 \%$, and 17-hydroxycorticosteriods more than 64 to $69 \% .^{1}$ Inferior petrosal sinus sampling is particularly useful in establishing a pituitary source for Cushing disease but is of less utility in cases of lateralizing the tumor. ${ }^{30}$

\section{Utility of MR Imaging in Cushing Disease}

Although MR imaging is the most sensitive imaging modality for assessing the pituitary, ${ }^{10,11,40}$ the reported experience in the evaluation of MR images obtained in patients with Cushing disease is variable, with a sensitivity ranging from 22 to $92 \%{ }^{5,10,11}$ Pituitary adenomas are classically categorized by size as either microadenomas $(<10 \mathrm{~mm})$ or macroadenomas $(\geq 10 \mathrm{~mm})$. Although the majority of pituitary adenomas are macroadenomas on diagnosis, ACTH-secreting adenomas tend to be microadenomas that are intrasellar in location. ${ }^{14,15}$

The limitations of MR imaging in visualizing pituitary adenomas can be due to several variables, including field

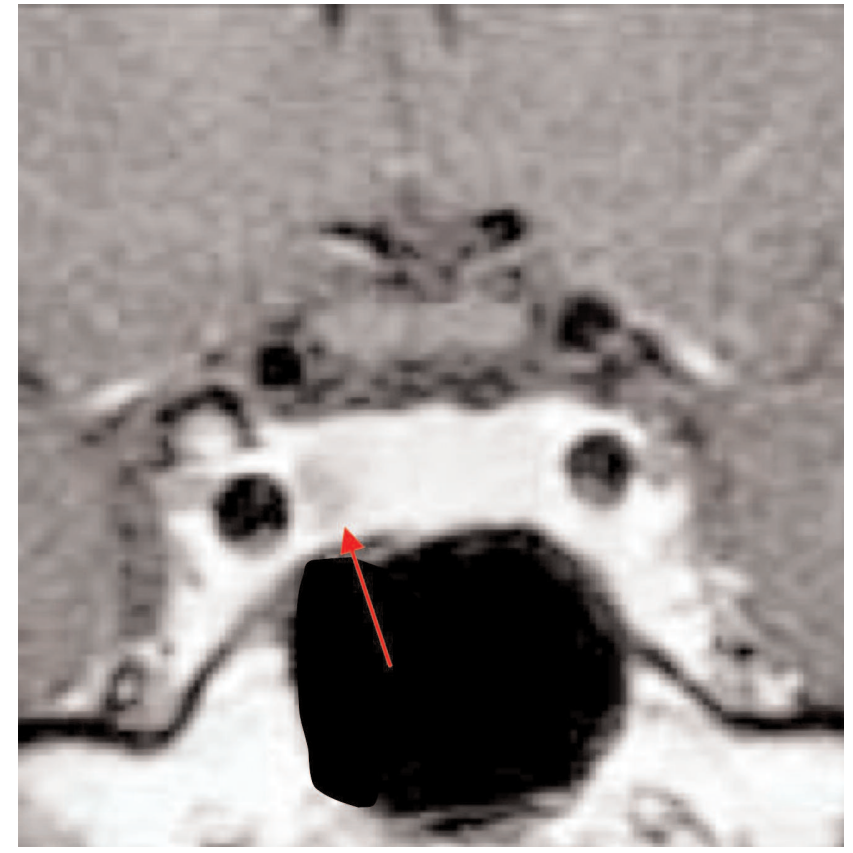

FIG. 1. Dynamic MR image of the pituitary gland, revealing a late area of hypodensity (arrow), possibly consistent with an adenoma.

strength, technique (choice of pulse sequence), and method of analysis (experience and number of reviewers, blindness to the definite diagnosis); additionally the characteristics of the tumor, including tumor size, can affect detection on conventional imaging.

On contrast-enhanced T1-weighted spin echo images, the tumors are usually round or oval and exhibit a loss of signal intensity compared with the normal portion of the pituitary gland due to differences in the dynamics between the tumor and normal pituitary gland. In many cases of MR imaging-negative Cushing disease, however, the more heavily T1-weighted signal of the pituitary adenoma is identical to that of the unaffected pituitary gland, necessitating further imaging investigation. In selected cases, T2weighted MR images can be of use when a tumor is not demonstrated on standard T1-contrasted images. On T2weighted imaging, the signal intensity of pituitary adenomas is slightly hyperintense to that of the normal anterior lobe, resembling the temporal cortex and white matter. ${ }^{4}$

In cases in which T1-weighted MR imaging is negative or the results are equivocal, a variety of more sensitive imaging tools have shown promise in detecting adenomas in patients with Cushing disease. Dynamic MR imaging (Fig. 1) takes advantage of the ACTH-secreting adenoma's characteristic slow enhancement compared with the normal pituitary. ${ }^{8}$ The authors of several studies have demonstrated that the timing of postcontrast imaging is critical in diagnosing an adenoma, because the maximal contrast of the adenoma-normal pituitary following Gd injection may occur in some cases within seconds and last for only a few minutes. ${ }^{38,43}$ Thus, a critical phase of contrast enhancement may be missed by conventional spin echo MR imaging, which usually takes several minutes to perform. Modern MR technology now allows further dynamic studies, such as acquisition of images within seconds after the injection 


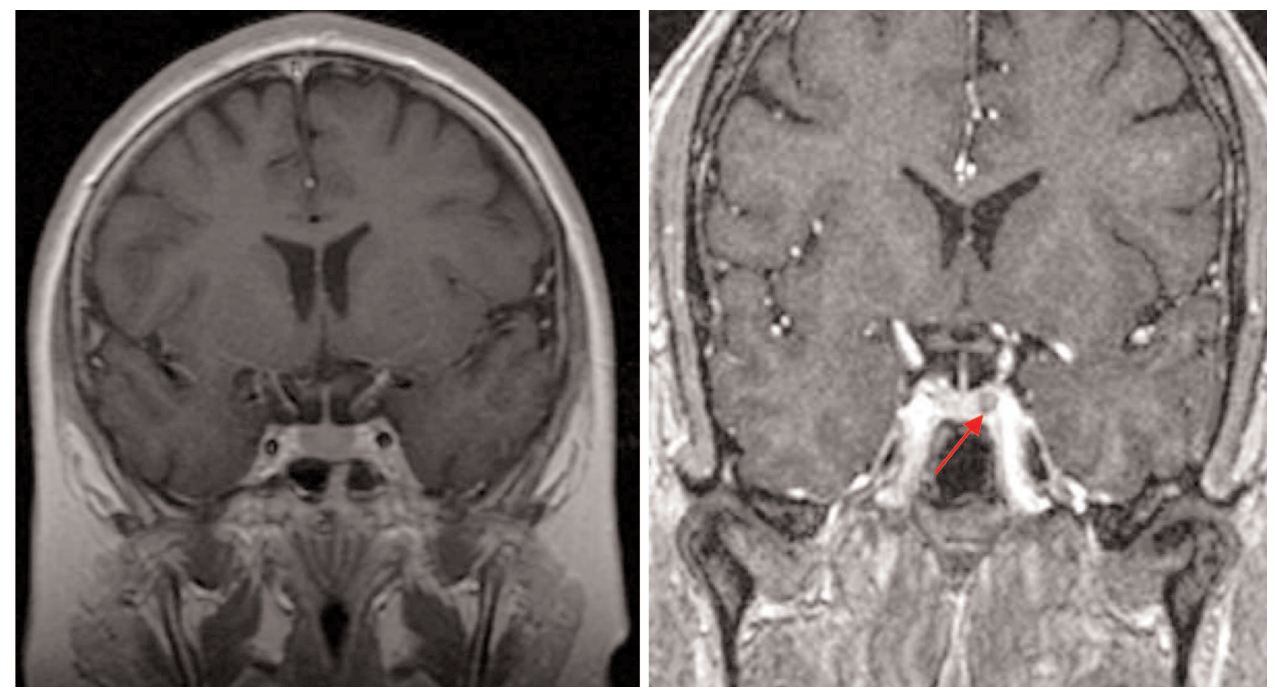

FIG. 2. Left: Gadolinium-enhanced spin echo MR image showing no evidence of an adenoma. Right: An SPGR MR image successfully revealing adenoma (arrow) in this patient with Cushing disease.

of Gd, allowing dynamic MR imaging to capture the early maximal contrast between tumors and normal pituitary tissue.

Initial studies involving dynamic spin echo imaging with a temporal resolution of 20 to 60 seconds demonstrated that the best contrast for microadenomas was obtained on earlyphase dynamic images, acquired 30 to 90 seconds after Gd injection, and the studies also showed that the contrast decreases on images obtained several minutes later. ${ }^{37}$ The results of newer studies performed in patients with pituitary microadenomas of different causes support this hypothesis, $, 18,37$ but most of these studies have been limited by small patient numbers, lack of controls, and the variability in the type of MR imaging technology. ${ }^{18}$ The true value of dynamic MR imaging in patients with Cushing disease thus remains to be determined.

Spoiled gradient recalled acquisition in the steady-state MR imaging (Fig. 2) involves acquiring thin image sections of 1-mm thickness (compared with $2.5-3 \mathrm{~mm}$ on standard spin echo images), using a spoiler gradient to shorten repetition time. ${ }^{32}$ The SPGR technique allows for a substantial improvement in the spatial resolution of images that are acquired. In a study of 30 children with Cushing disease, Batista et al. ${ }^{2}$ reported that the overall probability that postcontrast spin echo MR imaging would be positive in a child with surgically proven Cushing disease was $25 \%$, whereas the probability of a positive postcontrast SPGR MR imaging study in the same patient was $71 \%$. Similar data have been reported in adults as well. ${ }^{32}$

\section{Surgical Strategies in Patients With Negative MR Imaging}

Microscopic transsphenoidal surgery is the treatment of choice in patients with Cushing disease and is the first treatment in the majority of our patients. ${ }^{13,24}$ Over time, our strategy has gradually evolved to include the endoscopic approach in patients with negative MR imaging to facilitate exposure and resection, although we have had success with the microscope as well (Video 1).
VIDEO 1. Video identifying a tumor in a patient in whom MR imaging was negative. After a bloodless exposure of the sella, the surface of the pituitary gland is examined thoroughly for the presence of tumor. If no tumor is immediately visualized a vertical paramedian incision is made, with the dissection proceeding in a progressive posterior and lateral direction in an attempt to identify a tumor. If no tumor is identified, then the same maneuver is repeated via a paramedian incision on the contralateral side. If a tumor is still identified, then the inferior mesial portion of the gland is dissected via a transverse incision, leaving a central wedge of gland still attached to the pituitary stalk. The differences from the traditional microscopic approach are the more magnified views of areas that are out of a microscope's line of sight and the ability to move the endoscope in for dynamic views of areas of interest. With the 0 and $30^{\circ}$ endoscopes, the sellar floor, cavernous sinus walls, and diaphragm can be directly inspected. When the anatomy is not completely visualized, the $30^{\circ}$ endoscope can be used.

Click here to view with Windows Media Player and a broadband connection or here to view with RealPlayer.

Our standard approach now is to use a binasal three- or four-hand technique (in lieu of an endoscope holder), with a posterior septectomy preserving the middle turbinates unless the nasal cavity is exceptionally small. ${ }^{17}$

The advantage of the endoscopic exposure in patients with negative MR imaging is a broad exposure of the sella, permitting visualization and examination of the pituitary gland. Patients are positioned in a semirecumbent position $\left(\sim 20^{\circ}\right.$ back up) with the head placed in a horseshoe headrest. Patties soaked in 1:1000 epinephrine are placed between the middle turbinates and the septum prior to preparation and draping. After draping, the patties are removed, and using a 25-gauge 1.5-in needle or spinal needle, the middle turbinate, posterior portions of the septum and rostrum, and the region around the sphenopalatine foramen are injected submucosally with $0.2 \%$ ropivacaine with 1:200,000 epinephrine.

The $0^{\circ}$ endoscope is first used to inspect both nasal cavities. The side with the greater working space is chosen for the initial dissection of the posterior septum and for the sphenoidotomy (if there is a deviated septum, for example, 


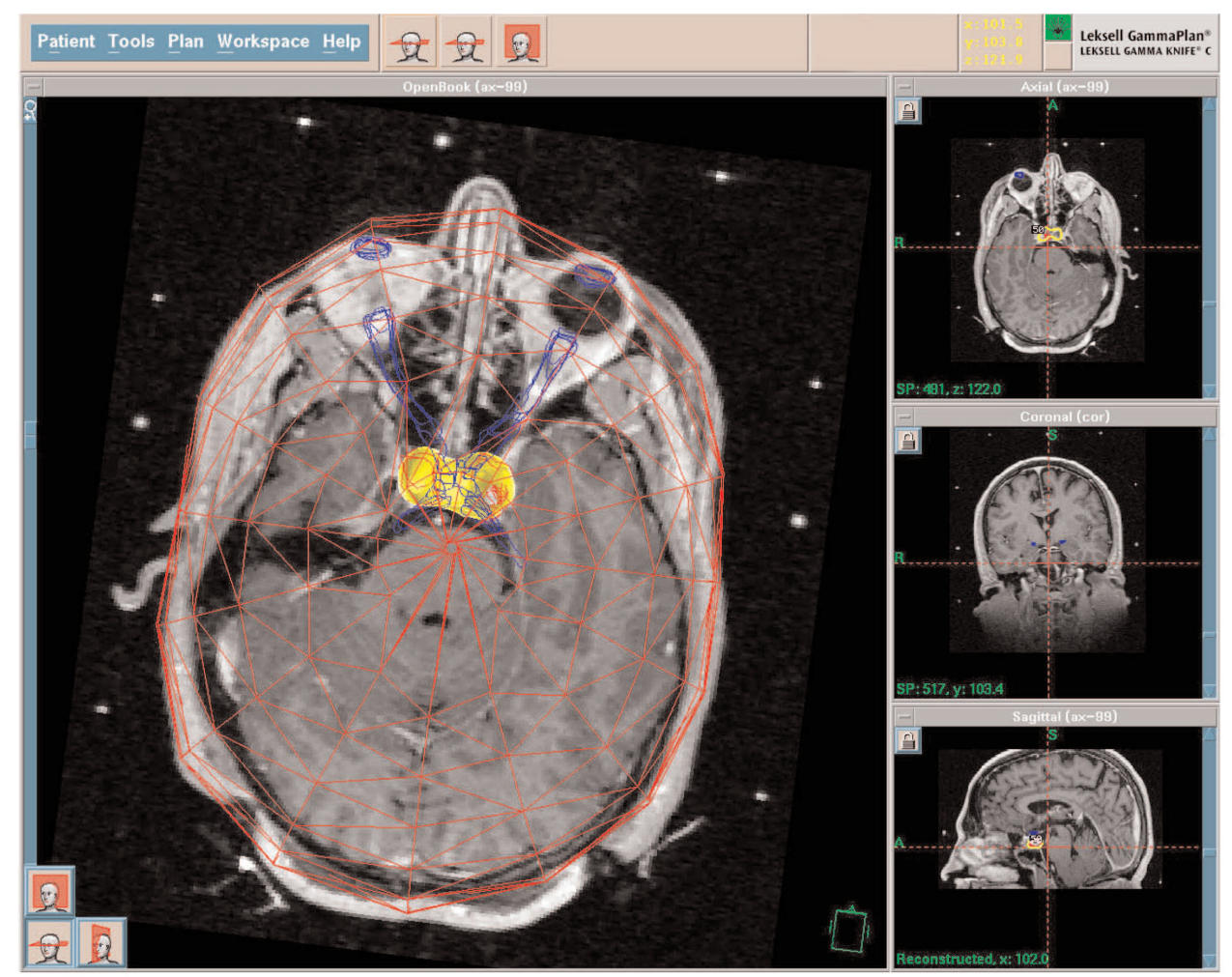

FIG. 3. A radiosurgical treatment plan used in patients with negative MR imaging results involves targeting the sella while shielding the optic nerves and cranial nerves within the cavernous sinus.

the wider nasal cavity is used). If the sides are equal in size, our preference is to perform the greater part of the dissection in the right naris. Prior to beginning the dissection, the endonasal anatomy is identified, including the middle and inferior turbinates, the choana, and, most important, the superior turbinates and sphenoid ostia. This initial orientation helps to prevent the undesirable breach of the anterior cranial fossa, as there is a tendency to deviate superiorly when a surgeon is inexperienced with the endoscope.

The middle turbinates are lateralized and the sphenoid ostium is identified in the inferior-third portion of the superior turbinate. The mucosa surrounding the sphenoid ostium is cauterized and the septum is reflected into the contralateral nasal cavity by detaching it from its junction with the sphenoid rostrum. This allows the contralateral sphenoid ostium to be identified, and the bone between the two ostia is removed. This initial sphenoidotomy is then enlarged, and a posterior septectomy is performed. We have found that the soft-tissue shaver provides a more rapid and precise removal of the septal mucosa than do the throughbiting instruments.

A wide anterior sphenoidotomy is performed including both sphenoid ostia and the lateral regions at the base of the sella. The superior limit should allow visualization of the planum sphenoidale, the optic protuberances, and the opticocarotid recesses. During tumor resection, because the endoscope will be positioned superolaterally, the sphenoidotomy will need to be large enough to accommodate the endoscope without obstructing the flow of instruments. The inferior limits of the sphenoidotomy must allow suction to pass freely to the floor of the sella. In general, the vomer does not need to be completely removed to provide this exposure, and its presence helps establish an anatomical midline if reoperation is necessary.

The panoramic view of the sphenoid anatomy provides information regarding the midline and limits of the sella. Under endoscopic guidance, the vomer and the midpoint between the carotid protuberances or the opticocarotid recesses can be used as midline markers. Once the intersphenoid sinus septae are removed, the carotid and optic protuberances are identified, as are the opticocarotid recesses, clivus, sella, and planum. We have found that all of these landmarks are not always visible. Nevertheless, enough of the anatomical landmarks are usually visible so that the sellar anatomy can be determined. If doubt remains, intraoperative video fluoroscopy is performed.

In general, the posterior septectomy and sphenoidotomy are performed using a two-handed mononostril technique, with the endoscope in one hand and an operative instrument in the other. The contralateral nostril is accessed at times, particularly during the septectomy, but most of the endoscopy and dissection is performed via one nostril. From this point on, the operation proceeds through a binasal three- or four-hand approach, with the endoscope and suction in one nostril and the operative instrument in the other. Interplay is required between the endoscopist and the surgeon. The endoscope should follow the instruments into and out of the nose and dynamically focus on the field of interest.

The sellar floor is then opened to the limits of the cavernous sinus laterally, the turberculum and planum are opened superiorly, and the sellar floor is opened inferiorly. 
Negative magnetic resonance imaging in Cushing disease

We have not found it necessary to use a drill for the sellar opening, and we often simply fracture the sellar floor or open it using a fine chisel. At times, a small vessel can be seen to exit the dura mater over the pituitary gland. We have found that this vessel correlates with the anatomical midline and can be used in addition to the other midline markers. The $0^{\circ}$ endoscope is used during most of the operation.

The key to tumor resection involves obtaining a bloodless surgical field. When the sella is opened, the surface of the pituitary gland is examined thoroughly for the presence of a tumor. If a tumor is identified, an attempt is made to remove the entire capsule. If an extracapsular dissection is not possible, the tumor resection proceeds in a manner similar to that of the microscopic adenomectomy, with removal of the inferior, lateral, and finally the superior portions of the tumor against the diaphragm. If no tumor is immediately visualized, a vertical paramedian incision is made with the dissection proceeding in a progressive posterior and lateral direction in an attempt to identify a tumor. If no tumor is identified, then the same maneuver is performed via a paramedian incision on the contralateral side. If, after this, no tumor is identified, the inferior mesial portion of the gland is then dissected through a transverse incision, leaving a central wedge of gland still attached to the pituitary stalk. The operation is typically considered complete at this stage in pediatric patients and women of childbearing age who desire fertility. In other patients, the decision to undertake a hypophysectomy is made on a case-by-case basis, depending on the patient's condition and prior operations and results of laboratory studies and inferior petrosal sinus sampling. The differences from the traditional microscopic approach are the more magnified views of areas that are out of a microscope's line of sight and the ability to move the endoscope in for dynamic views of areas of interest. With the 0 and $30^{\circ}$ endoscopes, the sellar floor, cavernous sinus walls, and diaphragm can be directly inspected. When the anatomy is not completely visualized, the $30^{\circ}$ endoscope can be used. In these situations intraoperative ultrasonography may also be useful in clarifying the relationship to the cavernous sinus and occasionally in determining the presence of tumor. ${ }^{46}$

Patients in whom remission is not achieved at surgery deserve mention. Repeated surgery for a total hypophysectomy is considered for adult patients, beyond their reproductive years, in whom a tumor was pathologically identified but in whom remission was not achieved. The Gamma Knife is considered for patients in whom no tumor was identified intraoperatively. In such cases, Oldfield et al. ${ }^{31}$ have reported on the use of multiple, blind incisions in the pituitary gland to infarct small tumors that may be present, a strategy that we have found useful in some patients.

If a CSF leak is noted during surgery, we place a fat graft within the sella. Appropriately sized fat grafts can be difficult to place within the nose, and at times a nasal speculum must be used to provide access. Often we will also insert a dural substitute against the diaphragm and in a subdural plane over the fat. If no CSF leakage is noted, we simply place Gelfoam within the sella. If adequate septal bone is not harvested intraoperatively (as is the norm), a tailored bioabsorbable graft is sized using a $0.5 \times 0.5$-in patty and placed in an extradural plane under the remaining sellar bone. In the case of a CSF leak, we usually do not fill the sphenoid sinus with fat; if we do, however, we first remove the sphenoid mucosa. Otherwise, every attempt is made to preserve the sphenoid mucosa, and it is disrupted over the sella only.

\section{Radiosurgery in MR Imaging- Negative Cushing Disease}

\section{Radiosurgery for Pituitary Adenomas}

Radiotherapy was originally the adjuvant treatment of choice in patients with recurrent or residual pituitary adenomas. However, because of its slower rate of hormonal normalization and increased incidence of associated complications, radiotherapy has fallen out of favor for the treatment of pituitary adenomas. ${ }^{12}$

Unlike traditional fractionated radiotherapy regimens, the idea behind radiosurgery is to deliver an overwhelming dose of radiation to a tumor in a single session. Image guidance and a steep falloff are used to spare the surrounding tissues from the harmful effects of radiation. Radiosurgery is performed using the Gamma Knife, a LINAC-based system, or proton beams produced by cyclotrons.

Gamma Knife surgery usually involves multiple isocenters of different beam diameter to achieve a dose plan that conforms to the irregular 3D volumes of most mass lesions..$^{20}$ The total number of isocenters may vary depending on the size, shape, and number of lesions. The recent version of the Gamma Knife, Perfexion, combines advances in dose planning, beam collimation, and robotic engineering, and it obviates the need to set coordinates manually for each isocenter. In LINAC-based radiosurgery, multiple radiation arcs are utilized to "crossfire" photon beams at a target defined in stereotactic space. ${ }^{28}$ Most of the systems functioning at present use nondynamic techniques in which the patient couch is set at an angle and the arc is moved around its radius to deliver radiation that enters the skull through many different points. Numerous techniques have been developed to enhance conformity of dose planning and delivery using LINAC-based systems. These include beam shaping and intensity modulation. Newer developments include the introduction of jaws, noncircular, and mini- and microleaf collimators. The conformal beam can be delivered with the micromultileaf collimator or conformal blocks.

Proton-beam radiosurgery takes advantage of the intrinsic superior dose distribution of protons compared with photons because of the Bragg peak at treatment depth. ${ }^{47}$ These facilities are available at a limited number of centers only due to financial, personnel, and logistical constraints. The effective delivery of radiation to a target requires clear and accurate imaging of that target. Over the past 20 years, significant advances have increased the efficacy and safety of radiosurgical treatment of pituitary lesions.

Tumor localization for dose planning is better achieved with enhanced coronal MR imaging than with computed tomography scanning. An MR imaging sequence consisting of postcontrast, thin-slice (for example, 1-mm) volume acquisition is typically utilized to define the tumor within the sellar region. In patients with a history of surgery, fatsuppression techniques can prove useful for differentiating tumor from surgical fat grafts. Computed tomography scanning is generally used in patients who cannot undergo 
MR imaging, for example, those with pacemakers. Positron emission tomography and higher-field strength MR imaging (for example, 3 tesla and higher) may further enhance radiosurgical targeting.

In the vast majority of cases, we use radiosurgery to treat patients in whom prior transsphenoidal microsurgery has failed. As such, it is useful to evaluate the preoperative MR images and discuss the surgical findings with the microsurgical team before treatment, particularly when determining which patients have tumors that may involve the cavernous sinus. Radiosurgery can be successful in achieving hormonal normalization in patients in whom MR imaging has been negative, and generally we use the entire sellar region (including the inferior dura) as a target in these cases (Fig. 3 ). In our experience with using radiosurgery to treat patients with Cushing disease, the remission rate has been approximately $54 \%$ in all patients, including those with negative MR imaging (mean dose to the sella $23 \mathrm{~Gy}$ ). ${ }^{16}$

Tumors that are suspected to involve the cavernous sinus deserve special mention. Although the tolerable limit to the cavernous sinus nerves is unknown, authors have described effective radiosurgical doses of between 19 and 23 Gy to this region without major side effects. ${ }^{19,23,26,33,41,42}$ Injury to the cavernous segment of the carotid artery is rare after radiosurgery, with few isolated case reports, and the nerves of the cavernous sinus appear to be relatively radioresistant.$^{21}$ In some cases, blocking patterns can also be used to effectuate radiation delivery while shielding vital structures. These patterns are often used to distort the peripheral isodose curves away from the optic apparatus because of the radiosensitivity of this structure around the optic apparatus and cavernous sinus.

The risk of major complications following radiosurgery is low. The most common complication is late-onset hypopituitarism, which can be seen in up to $30 \%$ of patients followed for Cushing disease ${ }^{16}$ However, the latency of such effects may be long ( $\geq 10$ years) and, as such, warrants continued neurological, endocrine, and radiological follow-up. The authors of a long-term study from the Karolinska Institute, with a mean follow-up of 17 years, reported a $72 \%$ incidence of hypopituitarism. ${ }^{44,45}$

\section{Conclusions}

Pituitary adenomas in Cushing disease can be challenging in cases in which MR imaging is negative. In such situations, it is critical to ensure that the diagnosis of Cushing disease is a correct one. The endoscope and radiosurgery are both valuable tools in achieving endocrine remission in patients with MR imaging-negative Cushing disease.

\section{References}

1. Arnaldi G, Angeli A, Atkinson AB, Bertagna X, Cavagnini F, Chrousos GP, et al: Diagnosis and complications of Cushing's syndrome: a consensus statement. J Clin Endocrinol Metab 88: 5593-5602, 2003

2. Batista D, Courkoutsakis NA, Oldfield EH, Griffin KJ, Keil M, Patronas NJ, et al: Detection of adrenocorticotropin-secreting pituitary adenomas by magnetic resonance imaging in children and adolescents with Cushing disease. J Clin Endocrinol Metab 90: 5134-5140, 2005

3. Bochicchio D, Losa M, Buchfelder M: Factors influencing the im- mediate and late outcome of Cushing's disease treated by transsphenoidal surgery: a retrospective study by the European Cushing's Disease Survey Group. J Clin Endocrinol Metab 80: 3114-3120, 1995

4. Bonneville JF, Bonneville F, Cattin F: Magnetic resonance imaging of pituitary adenomas. Eur Radiol 15:543-548, 2005

5. Buchfelder M, Nistor R, Fahlbusch R, Huk WJ: The accuracy of $\mathrm{CT}$ and MR evaluation of the sella turcica for detection of adrenocorticotropic hormone-secreting adenomas in Cushing disease. AJNR Am J Neuroradiol 14:1183-1190, 1993

6. Chen YM, Cintrón NM, Whitson PA: Long-term storage of salivary cortisol samples at room temperature. Clin Chem 38:304, 1992

7. Cohen-Gadol AA, Liu JK, Laws ER: Cushing's first case of transsphenoidal surgery: the launch of the pituitary surgery era. $\mathbf{J}$ Neurosurg 103:570-574, 2005

8. Davis WL, Lee JN, King BD, Harnsberger HR: Dynamic contrastenhanced MR imaging of the pituitary gland with fast spin-echo technique. J Magn Reson Imaging 4:509-511, 1994

9. Elster AD: High-resolution, dynamic pituitary MR imaging: standard of care or academic pastime? AJR Am J Radiol 163: 680-682, 1994

10. Escourolle H, Abecassis JP, Bertagna X, Guilhaume B, Pariente $\mathrm{D}$, Derome P, et al: Comparison of computerized tomography and magnetic resonance imaging for the examination of the pituitary gland in patients with Cushing's disease. Clin Endocrinol (Oxf) 39:307-313, 1993

11. Findling JW, Doppman JL: Biochemical and radiologic diagnosis of Cushing's syndrome. Endocrinol Metab Clin North Am 23: 511-537, 1994

12. Grigsby PW, Simpson JR, Stokes S, Marks JE, Fineberg B: Results of surgery and irradiation or irradiation alone for pituitary adenomas. J Neurooncol 6:129-134, 1988

13. Invitti C, Pecori Giraldi F, de Martin M, Cavagnini F: Diagnosis and management of Cushing's syndrome: results of an Italian multicentre study. Study Group of the Italian Society of Endocrinology on the Pathophysiology of the Hypothalamic-Pituitary-Adrenal Axis. J Clin Endocrinol Metab 84: 440-448, 1999

14. Jagannathan J, Dumont AS, Jane JA: Diagnosis and management of pediatric sellar lesions. Front Horm Res 34:83-104, 2006

15. Jagannathan J, Dumont AS, Jane JA, Laws ER: Pediatric sellar tumors: diagnostic procedures and management. Neurosurg Focus 18(6A):E6, 2005

16. Jagannathan J, Sheehan JP, Pouratian N, Laws ER, Steiner L, Vance ML: Gamma Knife surgery for Cushing's disease. J Neurosurg 106:980-987, 2007

17. Jane JA, Han J, Prevedello DM, Jagannathan J, Dumont AS, Laws ER: Perspectives on endoscopic transsphenoidal surgery. Neurosurg Focus 19(6):E2, 2005

18. Kucharczyk W, Bishop JE, Plewes DB, Keller MA, George S: Detection of pituitary microadenomas: comparison of dynamic keyhole fast spin-echo, unenhanced, and conventional contrastenhanced MR imaging. AJR Am J Neuroradiol 163:671-679, 1994

19. Kuo JS, Chen JC, Yu C, Zelman V, Giannotta SL, Petrovich Z, et al: Gamma knife radiosurgery for benign cavernous sinus tumors: quantitative analysis of treatment outcomes. Neurosurgery 54: 1385-1394, 2004

20. Laws ER, Sheehan JP, Sheehan JM, Jagnathan J, Jane JA, Oskouian R: Stereotactic radiosurgery for pituitary adenomas: a review of the literature. J Neurooncol 69:257-272, 2004

21. Lim YJ, Leem W, Park JT, Kim TS, Rhee BA, Kim GK: Cerebral infarction with ICA occlusion after Gamma Knife radiosurgery for pituitary adenoma: a case report. Stereotact Funct Neurosurg 72 (1 Suppl):132-139, 1999

22. Lindholm J: Cushing's syndrome: historical aspects. Pituitary 3:97-104, 2000

23. Liu AL, Wang C, Sun S, Wang M, Liu P: Gamma knife radiosur- 
gery for tumors involving the cavernous sinus. Stereotact Funct Neurosurg 83:45-51, 2005

24. Mampalam TJ, Tyrrell JB, Wilson CB: Transsphenoidal microsurgery for Cushing disease. A report of 216 cases. Ann Intern Med 109:487-493, 1988

25. Minami I, Tateno T, Yoshimoto T, Doi M, Izumiyama H, Akashi T, et al: Subclinical Cushings disease with amelioration of metabolic comorbidities after removal of pituitary tumor. Intern Med 45:1231-1235, 2006

26. Nakamura N, Shin M, Tago M, Terahara A, Kurita H, Nakagawa $\mathrm{K}$, et al: Gamma knife radiosurgery for cavernous hemangiomas in the cavernous sinus. Report of three cases. J Neurosurg 97 (5 Suppl):477-480, 2002

27. Nakane T, Kuwayama A, Watanabe M, Takahashi T, Kato T, Ichihara $\mathrm{K}$, et al: Long term results of transsphenoidal adenomectomy in patients with Cushing's disease. Neurosurgery 21:218-222, 1987

28. Nieman LK: Medical therapy of Cushing's disease. Pituitary 5:77-82, 2002

29. Oldfield EH, Chrousos GP, Schulte HM, Schaaf M, McKeever PE, Krudy AG, et al: Preoperative lateralization of ACTH-secreting pituitary microadenomas by bilateral and simultaneous inferior petrosal venous sinus sampling. N Engl J Med 312:100-103, 1985

30. Oldfield EH, Girton ME, Doppman JL: Absence of intercavernous venous mixing: evidence supporting lateralization of pituitary microadenomas by venous sampling. J Clin Endocrinol Metab 61:644-647, 1985

31. Oldfield EH, Vortmeyer AO: Development of a histological pseudocapsule and its use as a surgical capsule in the excision of pituitary tumors. J Neurosurg 104:7-19, 2006

32. Patronas N, Bulakbasi N, Stratakis CA, Lafferty A, Oldfield EH, Doppman J, et al: Spoiled gradient recalled acquisition in the steady state technique is superior to conventional postcontrast spin echo technique for magnetic resonance imaging detection of adrenocorticotropin-secreting pituitary tumors. J Clin Endocrinol Metab 88:1565-1569, 2003

33. Peker S, Kiliç T, Sengöz M, Pamir MN: Radiosurgical treatment of cavernous sinus cavernous haemangiomas. Acta Neurochir (Wien) 146:337-341, 2004

34. Putignano P, Dubini A, Toja P, Invitti C, Bonfanti S, Redaelli G, et al: Salivary cortisol measurement in normal-weight, obese and anorexic women: comparison with plasma cortisol. Eur J Endocrinol 145: 165-171, 2001

35. Putignano P, Toja P, Dubini A, Pecori Giraldi F, Corsello SM, Cavagnini F: Midnight salivary cortisol versus urinary free and midnight serum cortisol as screening tests for Cushing's syndrome. J Clin Endocrinol Metab 88:4153-4157, 2003

36. Riad-Fahmy D, Read GF, Walker RF: Salivary steroid assays for screening endocrine function. Postgrad Med J 56 (1 Suppl): $75-78,1980$
37. Sakamoto Y, Takahashi M: [New developments of neuro-imaging.] Gan To Kagaku Ryoho 18:168-173, 1991 (Jpn)

38. Sakamoto Y, Takahashi M, Korogi Y, Bussaka H, Ushio Y: Normal and abnormal pituitary glands: gadopentetate dimeglumine-enhanced MR imaging. Radiology 178:441-445, 1991

39. Salenave S, Gatta B, Pecheur S, San-Galli F, Visot A, Lasjaunias $\mathrm{P}$, et al: Pituitary magnetic resonance imaging findings do not influence surgical outcome in adrenocorticotropin-secreting microadenomas. J Clin Endocrinol Metab 89:3371-3376, 2004

40. Sheehan JM, Lopes MB, Sheehan JP, Ellegala D, Webb KM, Laws ER: Results of transsphenoidal surgery for Cushing's disease in patients with no histologically confirmed tumor. Neurosurgery 47:33-39, 2000

41. Sheehan JP, Jagannathan J, Pouratian N, Steiner L: Stereotactic radiosurgery for pituitary adenomas: a review of the literature and our experience. Front Horm Res 34:185-205, 2006

42. Sheehan JP, Kondziolka D, Flickinger J, Lunsford LD: Radiosurgery for residual or recurrent nonfunctioning pituitary adenoma. J Neurosurg 97 (5 Suppl):408-414, 2002

43. Stadnik T, Stevenaert A, Beckers A, Van Herzele D, Luypaert R, Buisseret T, et al: Contrast behavior between microadenoma and normal pituitary gland after gadolinium injection as a function of time at 1.5 T. Neuroradiology 34:184-189, 1992

44. Thorén M, Höybye C, Grenbäck E, Degerblad M, Rähn T, Hulting AL: The role of gamma knife radiosurgery in the management of pituitary adenomas. J Neurooncol 54:197-203, 2001

45. Ulfarsson E, Lindquist C, Roberts M, Rahn T, Lindquist M, Thorén $\mathrm{M}$, et al: Gamma knife radiosurgery for craniopharyngiomas: long-term results in the first Swedish patients. J Neurosurg 97 (5 Suppl):613-622, 2002

46. Watson JC, Shawker TH, Nieman LK, DeVroom HL, Doppman JL, Oldfield EH: Localization of pituitary adenomas by using intraoperative ultrasound in patients with Cushing's disease and no demonstrable pituitary tumor on magnetic resonance imaging. J Neurosurg 89:927-932, 1998

47. Woo YS, Isidori AM, Wat WZ, Kaltsas GA, Afshar F, Sabin I, et al: Clinical and biochemical characteristics of adrenocorticotropin-secreting macroadenomas. J Clin Endocrinol Metab 90:4963-4969, 2005

Manuscript submitted June 26, 2007.

Accepted July 26, 2007.

Address correspondence to: Jay Jagannathan, M.D., Department of Neurological Surgery, University of Virginia Health System, Charlottesville, Virginia 22908. email: jj5a@hscmail.mcc. virginia.edu. 